\title{
As revoluções das mídias: As transformações da era digital à luz do surgimento da imprensa
}

\section{Media revolutions: The transformations of the digital age in light of the invention of the printing press}

\author{
- JUlianA SCHMtTTa \\ Universidade Federal de São Paulo, Programa de Pós-Graduação em História. Guarulhos - SP, Brasil.
}

Barbier, F. (2018). A Europa de Gutenberg: O livro e a invenção da modernidade ocidental (séculos XIII-XVI) (G. C. C. de Sousa, trad.).

Edusp.

\section{RESUMO}

Esse texto é uma resenha do livro A Europa de Gutenberg: O Livro e a Invenção da Modernidade Ocidental (Séculos XIII-XVI), do historiador francês Frédéric Barbier, lançado na França em 2006 e no Brasil em 2018, em tradução publicada pela Edusp. O autor traça um panorama histórico do surgimento da prensa de tipos móveis, atentando para os processos sociais, econômicos e culturais que o antecedem e o sucedem, cobrindo, portanto, mais de três séculos. Com essa análise, sua proposta é elaborar um paralelo entre a revolução causada pela imprensa e a atual revolução digital, suas causas e consequências. Palavras-chave: História do livro, invenção da imprensa, comunicação e mídias

\footnotetext{
ABSTRACT

This text presents a review of the book Gutenberg's Europe: The Book and the Invention of Western Modernity, by the French historian Frédéric Barbier, released in France in 2006 and in Brazil in 2018 - a translated version to Portuguese published by Edusp. The author traces a historical panorama of the emergence of the movable-type printing press, focusing the social, economic and cultural processes that precede it and that succeed it, covering, therefore, more than three centuries. His aim is to draw a parallel between the revolution caused by the printing press and the current digital revolution, its causes and consequences. Keywords: History of the book, printing press, communication and media
}

\footnotetext{
Doutora em Letras pela Universidade de São Paulo (USP), com pós-doutorado em Artes, Cultura e Linguagens pela Universidade Federal de Juiz de Fora (UFJF). Mestranda em História na Universidade Federal de São Paulo (Unifesp). Orcid: https://orcid.org/00000001-5770-0436. E-mail: juschmittju@gmail.com
} 
A REVOLUÇÃO DIGITAL QUE ocorre desde o último quartel do século XX surpreende pela velocidade e pelos resultados. Até pouco tempo, teóricos dedicados a reconstituir a história das práticas da escrita e da leitura e analisar seu presente previam um futuro dos mais promissores. O advento da informática e a subsequente popularização da internet permitiu sonhar com um mundo em que o conhecimento seria largamente democratizado, em que a web seria o repositório de todos os saberes e o acesso a essa imensa biblioteca global seria fácil e amplo. Textos das mais variadas áreas e épocas seriam passíveis de intervenção pelos leitores, em um movimento de colaboração universal jamais visto, que daria início a uma nova era de compartilhamento quase infinito.

A despeito dessa utopia, o presente mostra que o crescente acesso à informação não significa necessariamente que as pessoas sejam bem-informadas: levantamento da Organização das Nações Unidas (ONU) de 2019 indica que mais da metade da população mundial usa a internet ("Estudo da ONU", 2019) - no entanto, grande parte do ambiente digital é hoje dominado pelas fakes news, por revisionismos e negacionismos e por empresas que captam inescrupulosamente os dados dos usuários para direcionamento de anúncios, como mostra o documentário $O$ Dilema das Redes (Orlowski, 2020), distribuído pela Netflix. O cenário é confuso e desaponta, principalmente se considerarmos todas as potencialidades da era digital. Faz parte do processo de uma revolução comunicacional e intelectual um período de dúvidas e obscurantismo? A crise é transitória ou perene?

São muitas as perguntas e olhar o passado em busca de um fenômeno similar a esse poderia servir como esboço para um prognóstico. É a esse propósito que se coloca o historiador francês Frédéric Barbier em seu livro A Europa de Gutenberg: O livro e a Invenção da Modernidade Ocidental (Séculos XIII-XVI), obra de 2006, publicada no Brasil pela Edusp em 2018. O autor explicita, nas primeiras páginas, seu objetivo de propor algumas chaves de entendimento sobre a revolução das mídias dos anos 2000 à luz do que considera a primeira revolução das mídias: 0 surgimento da prensa de tipos móveis, em meados do século XV.

Tendo isso em mente, ler a obra de Barbier nos permite identificar semelhanças entre dois momentos tão distantes. Para contar a história dos impressos, Barbier utiliza termos familiares ao leitor contemporâneo, como hardware, ao falar dos objetos e do maquinário, e software, ao falar de seu conteúdo; start-ups, para as primeiras oficinas de impressão e editoração, e paper valley para denominar o Vale do Reno, região da Mogúncia, berço da invenção de Gutenberg. Chega a evocar a ideia do livro-máquina, ou seja, o livro impresso como principal ferramenta da racionalidade durante cinco séculos, função que será ocupada pelo computador e pelas memórias digitais posteriormente. 
Essa insistência em elaborar paralelos, empregando o vocabulário da era digital atual, soa um pouco forçada para os leitores da historiografia do livro, mas pode ser atraente ao público leigo. Também ajuda, nesse sentido, o tom ensaístico do texto, que narra com fluidez as diferentes etapas do processo de surgimento da nova mídia. Para transportar seu leitor para o passado, Barbier demonstra seu profundo domínio do tema e reconstitui, com detalhes nas descrições, a paisagem urbana que ajudou a forjar o cenário ideal para a produção e o consumo dos impressos por volta de 1450. A obra, como um todo, revela-se um tour de force da erudição de seu autor. Discípulo do prestigiado historiador do livro Henri-Jean Martin (que é frequentemente citado), Frédéric Barbier é pesquisador do Centre National de la Recherche Scientifique, na França, autor de inúmeros trabalhos sobre a história da escrita e da imprensa, o desenvolvimento do mercado editorial, a formação das bibliotecas, entre outros assuntos afins, que pesquisa desde a década de 1970. Em A Europa de Gutenberg, Barbier mostra como a consolidação de uma cultura do texto impresso só foi possível porque foi acompanhada de uma transformação no modo de se pensar o acesso à informação. "O fenômeno parece tão notável que é equiparado em importância à queda do Império Bizantino e à descoberta do Novo Mundo, eventos com os quais se encerra a cronologia canônica da Idade Média" (p. 241), afirma o autor.

Os aspectos econômicos, sociais, geográficos e políticos explorados no livro são diferentes camadas que se interpuseram e possibilitaram que, em algumas décadas, fossem totalmente mudadas a forma da transmissão de dados, a comunicação e a troca de saberes. O autor, no entanto, elabora sua análise no tempo longo dessas modificações, cobrindo mais de trezentos anos. Esse recorte é divido em três partes: o período anterior à invenção de Gutenberg, que forneceu o terreno fértil para que a revolução ocorresse (a partir do século XII); o momento em que ela acontece de fato, com todas as suas implicações (século XV), e seus desdobramentos posteriores, evidenciando o impacto da nova mídia (as décadas seguintes). A ênfase, portanto, é no processo revolucionário e não no evento em si.

A primeira parte, "Gutenberg antes de Gutenberg", remonta às condições que permitiram o desenvolvimento de uma cultura escrita na Baixa Idade Média e possibilitaram que ela desse origem a um novo mercado de produção de textos. A cidade medieval surge, aqui, como espaço-chave desse processo, ao multiplicar suas demandas pelos documentos escritos, tanto de caráter administrativo, quanto de registros comerciais. É lá que a presença física e visível do manuscrito se multiplica e o texto escrito, tanto em latim quanto nas línguas vernáculas, passa por reformulações importantes, que aprimoram sua legibilidade, além de fazer parte de diferentes esferas da vida comum. Os atos 
de ler e escrever deixam de ser exclusividade dos clérigos e o objeto livro muda de status e se transforma em artigo colecionável.

A segunda parte mostra como esse cenário favorável possibilita a criação experimental de técnicas diferentes de confecção de textos. É "O Tempo das Start-Ups", como Barbier intitula o capítulo 2, fazendo uma analogia com a atividade empreendedora característica dos anos 2000. A difusão do uso do papel, o surgimento de uma indústria europeia que substitui o pergaminho, a produção maciça de imagens pela técnica da xilogravura e o protótipo de um consumo de massa, observado nas ocasiões de grandes peregrinações, são alguns dos fatores que motivam as buscas por inovações. É nesse contexto que atuam Johann Gutenberg e seus patrocinadores. Parte significativa desse capítulo é dedicada a explicar a articulação entre os desenvolvimentos que possibilitaram a revolução midiática causada pela prensa de tipos móveis e o capitalismo incipiente. Barbier deixa claro o papel crucial dos investidores que se lançaram nesse empreendimento de alto risco, apostando em tecnologias sem antecedentes e cujo produto não tinha ainda mercado constituído:

Com a imprensa, adentramos um sistema de produção manufatureira no qual o papel do capitalista se torna muito mais importante do que na época do manuscrito... Com o aumento da produção, editar um livro passa a ser uma operação contábil, industrial e comercial cada vez mais complexa. (pp. 215, 228)

"A Primeira Revolução das Mídias", terceiro e último capítulo, avalia o impacto da nova mídia nas décadas seguintes ao seu surgimento. Da Mogúncia, rapidamente as tipografias se alastram para os grandes centros urbanos e ganham, em poucos anos, toda a Europa Ocidental. Acompanham esse movimento todos os ofícios agregados à produção, como editores, tipógrafos, gravuristas, tradutores, revisores, distribuidores, livreiros. Aos poucos, a estética e a configuração dos impressos se afastam do modelo dos manuscritos, formando uma linguagem própria que inclui os formatos dos tipos e os precedentes do design gráfico, mudando não só a natureza do objeto que sai das prensas, mas sua relação com o consumidor. São múltiplas as consequências da disseminação da cultura do impresso, descritas minuciosamente por Barbier, como a gradual substituição do latim pelas línguas vernáculas, o que indica o considerável aumento do público leitor.

Duas teses abordadas pelo autor nos parecem particularmente interessantes por sua aplicação como foreshadowing do futuro da comunicação. Uma é a do imperialismo comunicacional, baseada na concentração da atividade tipográfica em alguns centros urbanos que, por isso, se tornariam polos de circulação de 
ideias e de exploração das mídias - em detrimento dos locais às margens dessa produção, que apenas a consomem. A segunda propõe que a lógica da transmissão dos saberes pelo impresso permitiu o surgimento do jornalismo, ao impor um novo tempo dos acontecimentos: o tempo real, no qual a publicização dos eventos e os comentários a seu respeito passam a ocorrer quase simultaneamente.

As potencialidades do impresso foram percebidas de imediato pelas instâncias do poder e o manejo das atividades relativas a ele estiveram em pauta desde seu início, como as outorgas de privilégios editoriais, a censura dos conteúdos, a regulamentação dos ofícios, a fiscalização das edições e de sua comercialização, assim como as questões relativas à propriedade intelectual e ao direito autoral. Mas a imensa produção de impressos em poucos anos e a impossibilidade de controlar completamente a difusão da informação promove o que Barbier chama de "krach das mídias": "tal como sucede hoje com a tela e a internet, o sistema dos conhecimentos parece perder sua coesão em proveito de uma espécie de caos potencialmente subversivo" (p. 365). É quando a coletividade se vê diante de uma quantidade de informações produzidas tão rápido e que circulam tão freneticamente - mas que ela ainda não tem meios para absorver.

A expressão empregada por Barbier, "krach das mídias", é adaptada de Paul Virilio, que escreve, em artigo de 1998, sobre a superprodução imagética das telecomunicações e da internet, às quais estamos expostos atualmente. $\mathrm{O}$ contato desenfreado e constante com essas imagens não causaria uma percepção mais detalhada e sofisticada do mundo, segundo Virillo (1998), mas seu efeito contrário: "a ameaça de uma cegueira coletiva da humanidade, a possibilidade inédita de uma derrota dos fatos e de uma desorientação de nossa relação com a realidade" (para. 32). No caso da invenção de Gutenberg no século XV, o resultado do "krach das mídias" foi, de acordo com Barbier, nada menos que a modernidade ocidental. Essa avaliação talvez seja um ponto de luz no obscurantismo dos nossos dias. $\mathbf{M}$

\section{REFERÊNCIAS}

Estudo da ONU revela que mundo tem abismo digital de gênero. (2019, 6 de novembro). ONU News. https://bit.ly/3nBob73

Orlowski, J. (Diretor). (2020). O dilema das redes [Filme]. Exposure Labs. Virilio, P. (1998, março). Eil pour œil, ou le krach des images. Le Monde Diplomatique. https://bit.ly/36MhgRL
${ }^{1}$ No original: "Cest la menace d'un aveuglement, d'une cécité collective de l'humanité, la possibilité inouïe d'une défaite des faits et, donc, d'une désorientation de notre rapport au réel". Tradução da autora.

Artigo recebido em 18 de novembro de 2020 e aprovado em 8 de março de 2021. 